\title{
Glauber antropófago: mal de archivo, del manifiesto Pau-Brasil a Di-Glauber
}

Rodrigo López

Universidad de Buenos Aires, Argentina

Fecha de recepción: diciembre 2018. Fecha de aceptación: junio 2019.

\begin{abstract}
Resumen
El Modernismo brasileño, con el ímpetu característicamente vanguardista propio de la década de 1920, delata la artificialidad de la tradición nacionalista brasileña y la abre a nuevas posibilidades de uso: al yuxtaponerla con las corrientes modernizadoras del siglo XX, subvierte el orden de este archivo y da lugar a una nueva y descolocada identidad nacional. Di-Glauber (1977), un documental poco estudiado por la crítica especializada en la filmografía de Glauber Rocha, ofrece la oportunidad de abordar la realización cinematográfica de una operación sobre dicha tradición cultural. A través de una relectura y un homenaje elegíaco de la figura y la obra del pintor Emiliano Di Cavalcanti, Rocha pliega los procedimientos del Modernismo sobre sí mismos, abriendo el archivo de Brasil a la experimentación de un film que reivindica para sí la fuerza disruptiva de su legado artístico.
\end{abstract}

\section{Glauber antropophagist: fever archive, from Manifesto of Pau-Brasil Poetry to Di-Glauber}

\begin{abstract}
The Brazilian Modernism, with its characteristically vanguardist impulse of the decade of the 1920 s, reveals the artificiality of the Brazilian nationalistic tradition and opens up new possibilities of usage: by juxtaposing it to the modernizing currents of the twentieth century, the order of this archive is subverted and a new and misplaced national identity takes place. Di-Glauber (1977), an often disregarded documentary by specialized critics in the filmography of Glauber Rocha, offers the opportunity to study the cinematographic realization of an intervention over the aforementioned cultural tradition. Through a re-reading and an elegiac homage to the figure and oeuvre of painter Emiliano Di Cavalcanti, Rocha turns the Modernist procedures over themselves, thus opening the Brazilian archive to the experimentation of a film that claims for itself the disruptive force of its artistic legacy.
\end{abstract}

\section{Palabras clave:}

modernismo antropofagia de Andrade Rocha

Di Cavalcanti

Keywords:

modernism Anthropophagy de Andrade Rocha Di Cavalcanti 
Palavras chave:

modernismo antropofagia de Andrade

Rocha

Di Cavalcanti

\section{Resumo}

O modernismo brasileiro, com o impetu carateristico do modernismo da década de 1920 , revela a artificialidade da tradição nacionalista brasileira e abre-a a novas possibilidades de uso: justapondo-a a correntes modernizadorasdo século XX, subverte a ordem desse arquivo e dá origem a uma identidade nacional nova e extraviada. Di-Glauber (1977), um documentário pouco estudado por críticos especializados na filmografia de Glauber Rocha, oferece a oportunidade de abordar a realização cinematográfica de uma operação sobre essa tradição cultural. Através de uma releitura e de uma homenagem elegíaca à figura e ao trabalho do pintor Emiliano Di Cavalcanti, Rocha dobra os procedimentos do Modernismo em si, abrindo o arquivo do Brasil à experimentação de um filme que reivindica por si mesmo a força disruptiva de seu legado artístico.

"Consideramos a 1922 como el año de inicio de una revolución cultural en Brasil. El exponente principal de ese período fue Oswald de Andrade. Su trabajo cultural [...] fue definido por él como antropofágico, en referencia a la tradición de los indios caníbales. Así como aquellos comían a los hombres blancos, él decía haberse comido toda la cultura brasileña y colonial."

Glauber Rocha, "Tropicalismo, antropofagia, mito, ideograma"

\section{I}

Dice Jacques Derrida, en Mal de archivo. Una impresión freudiana, que todo archivo es a la vez conservador e instituyente: el archivo no solo almacena y clasifica, sino que además instaura sus propias leyes de almacenamiento, articulando en unidad homogénea los elementos archivados: "en el cruce de lo topológico y de lo nomológico, del lugar y de la ley, del soporte y de la autoridad, una escena de domiciliación se hace a la vez visible e invisible" (Derrida, 1997:11). A riesgo de exponer la fragilidad constitutiva de su unidad, el archivo debe enmascarar la arbitrariedad de las leyes que habilitan su conformación: paradójicamente, el archivo archiva un olvido, el olvido de su propio momento inaugural: "Desde que hay lo Uno, hay asesinato, herida, traumatismo. Lo Uno [...] comporta en sí mismo, guardándola de este modo, la alteridad o la diferencia de sí (la diferencia consigo) que le hace Uno" (1997: 86). El mal de archivo, entonces, implica que este alberga sus propios límites, su propia y radical destrucción: en posición éxtima, es decir, exterior al archivo, pero archivada en su más íntima interioridad, la pulsión de muerte resulta inherente al proceso de la archivación y amenaza con reducir aquello mismo que produce.

Se entiende al archivo, de este modo, no como un corpus de figuras, documentos u obras, sino como una lógica de clasificación y ordenamiento, inherentemente imposibilitada de cierre, que aspira a hacer, de las fuerzas vivas de una cultura, una unívoca y homogeneizada tradición. El Modernismo brasileño, con el ímpetu propio de las vanguardias de la década de 1920, revela el mal de archivo del Brasil y entredice la tradición cultural patriótica heredada, paradigmáticamente, de la empresa romántica y nacionalista del emperador Pedro II (1825-1891). Elías Palti señala la convergencia, en el siglo XIX, entre los procesos de consolidación de una identidad nacional brasileña y de afirmación de un aparato estatal centralizado, convergencia que encuentra su concreción en una tradición historiográfica que da lugar a un "nacionalismo oficial": en sus propios términos, "esto permitió y sirvió de sustento en Brasil para una alianza entre el saber histórico y el poder político que cobró forma institucional con el Instituto Histórico y Geográfico Brasileño [fundado y presidido por Pedro II en 1838]" (Palti 1996: 57). El Modernismo delata la artificialidad del archivo nacionalista imperante y abre sus elementos a nuevas 


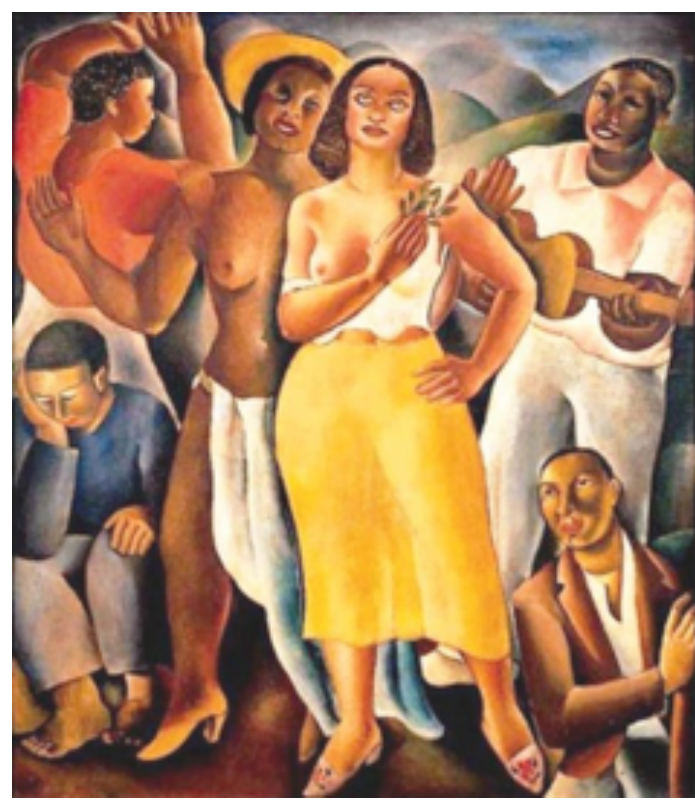

Samba (1925).

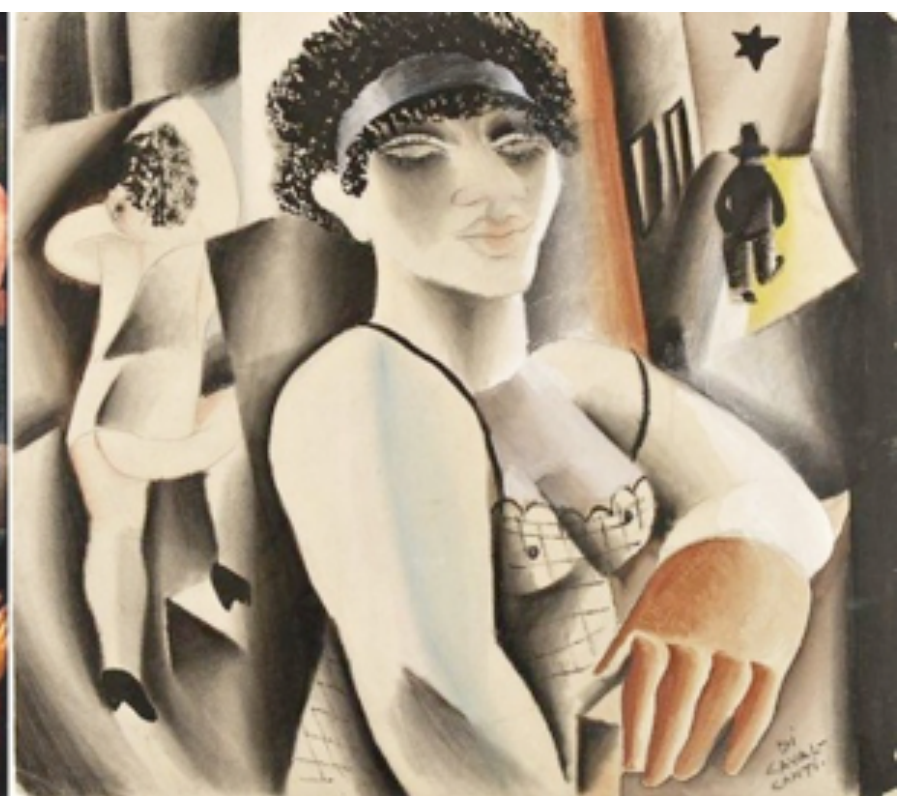

Mulatas (1928).

posibilidades de uso: al yuxtaponerlo con las corrientes modernizadoras del siglo XX, subvierte el orden de este archivo y da lugar a una nueva y descolocada identidad brasileña; en términos de Derrida: "[al archivo] nunca se lo podrá objetivar sin resto. El archivero produce archivo, y es por esto que el archivo no cierra jamás. Se abre desde el porvenir" (Derrida 1997: 75). Di-Glauber (1977), un documental poco estudiado por la crítica especializada en la filmografía de Glauber Rocha, ofrece la oportunidad de abordar la realización cinematográfica de una operación sobre la tradición cultural brasileña. A través de una relectura y de un homenaje elegíaco de la figura y la obra del pintor Emiliano Di Cavalcanti (1897-1976), Rocha pliega los procedimientos del Modernismo sobre sí mismos, abriendo el archivo del Brasil a la experimentación de un film que reivindica para sí la fuerza disruptiva de su legado artístico.

\section{II}

En el Manifiesto Pau-Brasil (1924), Oswald de Andrade instaura las bases vanguardistas del Modernismo: "La poesía existe en los hechos. Las casuchas de azafrán y ocre en los verdes de la Favela. [...] El Carnaval de Río. [...] Pau-Brasil. Wagner naufraga ante las escuelas de samba de Botafogo" (Andrade O., 2008:19). Indaga en los márgenes del archivo nacionalista heredado, para así articular una identidad y un arte auténticamente brasileños: apela a la cotidianeidad frente al sublime ideal europeo: "Contra el gabinetismo, la práctica culta de la vida. [...] Dividamos: Poesía de importación. Y la poesía Pau-Brasil, de exportación" (2008: 21). El manifiesto sintetiza una propuesta marcadamente estética, orientada a la irrupción de un arte, pasible de exportación como manifestación autóctona, que rompa con la tradición docta y europeizante del archivo nacional: "La reacción contra el tema invasor. [...] Un cuadro son líneas y colores. [...] La Poesía Pau-Brasil es un comedor dominguero, con pajaritos cantando" (2008: 23). Ahora bien, la búsqueda de identidad y arte autóctonos no se desliga del contexto moderno en que surge: el Modernismo tensiona los rasgos locales del Brasil con los lenguajes estéticos vanguardistas y las innovaciones tecnológicas que signan aquellos de principios del siglo XX: "Una visión que golpee en los cilindros de los molinos, en las turbinas eléctricas, [...] sin perder de vista el Museo Nacional. Pau-Brasil" (2008: 24). 
En línea con el Manifiesto Pau-Brasil, la renovación modernista de las artes plásticas brasileñas conlleva "la preocupación respecto a las nuevas corrientes estéticas vigentes en París, y la necesidad de reflejar la tierra natal (internacionalismo y nativismo)" (Amaral, 1978: XII). Ilustra este doble eje la obra de Emiliano Di Cavalcanti, cuya búsqueda de autenticidad local no cede a un impostado esencialismo originario, sino que se formula desde la experiencia contemporánea de la cultura brasileña y su contexto modernizador. Mario de Andrade, figura icónica de la irrupción modernista en Brasil, explica de esta manera la intervención de Di Cavalcanti en el archivo nacional: "sin atenerse a ninguna tesis nacionalista, es el más exacto pintor de las cosas nacionales. No confundió el Brasil con el paisaje, y en vez de Pan de Azúcar nos dio sambas, en cambio de cocoteros, mulatas, negros y carnavales" (Andrade M., 1978: 26). Su pintura encuentra, en los márgenes del archivo nacionalista, en los mulatos, sus sambas y carnavales, una manifestación propia de la identidad brasileña: entre las obras de Di Cavalcanti contemporáneas al Manifiesto Pau-Brasil, Samba (1925) plasma, en la calidez de los colores y el erotismo de los cuerpos expuestos, la vivacidad de una cultura autóctona, musical, apegada a la vivencia cotidiana del mulato. Mulatas (1928), por otra parte, tensiona este material local con los lenguajes vanguardistas europeos: remite al escenario urbano del burdel, en el cual coexisten los ángulos marcados y distorsionados característicos del expresionismo, junto al traje y galera del visitante, con la sensualidad de las formas redondeadas, acentuadas y voluptuosas de los cuerpos de las mulatas.

La impronta de vanguardismo estético, con que Oswald de Andrade dota al Manifiesto Pau-Brasil, vira hacia el vanguardismo político en el Manifiesto antropófago (1928): la ruptura ya no se limita a la tradición artística de Brasil sino que abarca las instituciones socio-culturales del mundo entero: "Sólo la Antropofagia nos une. Socialmente. Económicamente. Filosóficamente. Única ley del mundo" (Andrade O., 2008: 39). Oswald de Andrade lee el archivo de Brasil a contrapelo, y encuentra en la primitiva cultura tupí la posibilidad de una experiencia vital ajena a los sistemas racionalistas del orden occidental: "Oswald empleó al indio (a la figura del indio) para hacer la crítica del Estado, la sociedad patriarcal, el moralismo, la Estética y las creencias. [...] Propone el montaje, la superposición sarcástica y burlesca que hace estallar los ordenamientos cronológicos y las narraciones lógicas" (Aguilar, 2010). Antropofagia, de esta manera, implica deglutir el legado cultural universal, incorporarlo todo a fin de potenciar un gesto transgresor singularmente brasileño.

Dice Oswald de Andrade: “De Williams James a Voronoff. La transfiguración del Tabú en tótem" (2008: 44). Según el mito freudiano, el momento inaugural de la sociedad descansa en un asesinato caníbal -el del padre erigido en tótem- y en un acto de prohibición -el del incesto condenado como tabú-. Transfigurar el Tabú en Tótem supone subvertir este orden racional y occidental, como bien señala Aguilar: "la idea de que el hombre primitivo está en nosotros no como un origen que se remonta a tiempos lejanos sino como la materia que se resiste a ser eliminada, esa dimensión loca y lúdica que se revela con toda su fuerza frente a la racionalización dominadora y patriarcal" (2010: 20). Andrade torna visibles, así, los elementos reprimidos en el archivo de Brasil; en términos de Derrida, la pulsión de muerte sobre la que este se constituye: "La justicia: codificación de la venganza. La ciencia: codificación de la Magia. Antropofagia. La transformación permanente del Tabú en tótem" (Andrade O., 2008: 41). Liberar el tabú connota la liberación del cuerpo, ya no atado a la lógica racional sino abierto a la experiencia táctil: "se niega a concebir el espíritu sin cuerpo. El antropomorfismo. Necesidad de la vacuna antropofágica. [...] Recorridos. Recorridos" (2008: 41). El primitivismo antropófago, de esta manera, se inscribe en la contemporaneidad moderna mediante un montaje anacrónico que abre el archivo de Brasil a un nuevo y descolocado uso. 


\section{III}

Raúl Antelo caracteriza a Glauber Rocha como un caníbal, en la línea antropofágica inaugurada por Oswald de Andrade. Frente a la crítica que Ángel Rama dirige a Deus e o Diabona Terra do Sol (1964) -en la que condena "los errores de una mimetización demasiado evidente sobre las grandes obras del cine extranjero" (Antelo, 2014: 72)-, Antelo sostiene que el film exhibe la potencia juvenil y radical de un arte que deglute sin piedad a Eisenstein, Welles, Visconti, Buñuel, Godard o Rosellini. El film, que relata las peripecias de un sertanero de principios de siglo XX, sin privarse de recursos cinematográficos que evocan, por ejemplo, secuencias de ¡Que viva México! de Eisenstein, suscita consideraciones contrapuestas entre ambos críticos: donde Rama ve "errores del montaje y de una técnica lenta y barroca de elaboración" (2014: 78), Antelo reconoce la fuerza iconoclasta de la desmesura, de la voracidad, en términos de Rocha, de una estética del hambre que no se traduce en sumisión reverencial a modelos prestigiados, europeos, sino en puestas en transe de las representaciones artísticas de lo local y lo global, de lo primitivo y lo moderno. La persistencia vanguardista del primitivismo antropófago, tal como lo concibe Oswald de Andrade, en el escenario racionalista del siglo XX, implica una singular concepción de modernidad, propiamente latinoamericana: "contra la modernidad periférica, la excentricidad y el descentramiento. [...] No hay modernidad (no puede haberla en singular, porque la modernidad no es un hecho histórico sino una construcción teórica), sino modernidades" (Link, 2009: 137). La desmesura antropofágica de la experimentación fílmica de Rocha, en estos términos, se traduce en barroquización de la razón moderna, en descentramiento cinematográfico de la distinción valorativa entre centro y periferia instaurada por la Modernidad.

Además de figura paradigmática del Cinema Novo -movimiento colectivo de cineastas, constituido alrededor de la década de 1960, donde la cinefilia convive con la preocupación nacional, la estética moderna con el compromiso político-, Rocha se erige como su más consistente teorizador. En 1967, publica el artículo "Tricontinental" en Cahiers du cinéma, la mítica revista parisina donde figuras como Godard o Truffaut, entre otros, comenzaron sus carreras como críticos. Allí hace referencia a su propia posición de cineasta, escindido entre la realidad nacional de Brasil y el escenario cinematográfico global. Sostiene que los cineastas independientes brasileños, entre los que se cuenta, desconocen el respeto religioso por el cine y "aun siendo zurdos, agarraron las cámaras. [...] la técnica del cine pasado y del cine actual del mundo desarrollado me interesa en la medida en que puedo 'instrumentalizarla"' (Rocha, 2011: 75). Un año después, en el Festival de Cinema do Terceiro Mondo de Pesaro, plantea el interrogante en términos de orientación teórico-práctica de filmación: "en torno al Cinema Novo, que optó por enfrentar la verdad brasileña, surge un segundo desafío: ¿cuál es el lenguaje original a usar, una vez rechazado el lenguaje de imitación?" (2011: 90). La referencia a la antropofagia operará como respuesta posible.

En "Tropicalismo, antropofagia, mito, ideograma", de 1969, Rocha recupera el legado teórico de Oswald de Andrade y caracteriza a la antropofagia como la manifestación más importante de la cultura brasileña. En línea con los manifiestos Pau-Brasil y Antropófago, aspira a descolocar, con su práctica cinematográfica, el archivo nacionalista del Brasil. Su punto de partida lo constituye la constatación del estado de subdesarrollo económico y cultural de la historia nacional: "tenemos una tradición nacional-fascista, que luego se transformó en nacional-democrática; pero cuando el país descubrió el subdesarrollo, el nacionalismo utópico entró en crisis y cayó" (Rocha, 2011: 116). Su objetivo, superar el subdesarrollo con los mismos medios del subdesarrollo: la antropofagia le provee una vía de acción, le permite deglutir las tradiciones culturales heredadas: 


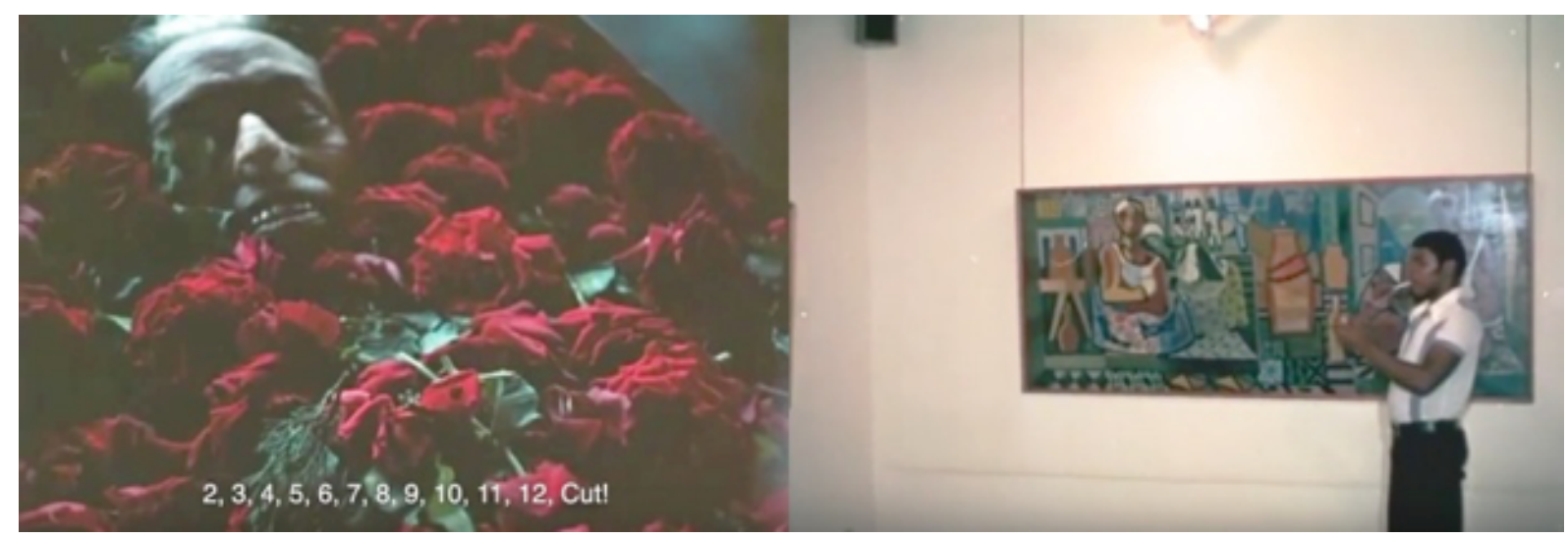

El descubrimiento antropofágico fue una revelación: generó conciencia, una actitud frente a la cultura colonial que no consistió en el rechazo de la cultura occidental, [...] [sino en] la ingestión de los métodos fundamentales de una cultura completa y compleja, pero también la transformación [...] a través de la utilización y la elaboración de la política correcta. (2011: 116)

La originalidad del Cinema Novo, para Rocha, reside en una estética del hambre: si el hambre conforma la normalidad de la subdesarrollada sociedad brasileña, este mismo hambre motiva el impulso antropofágico del cineasta, al momento de tratar la realidad local con cuanto recurso formal halle a su alcance: "las raíces indias y negras del pueblo latinoamericano deben ser asumidas como la única fuerza desarrollada de este continente. [...] La cultura popular no es lo que técnicamente se llama folclore, sino el lenguaje popular de una permanente rebelión histórica" (2011: 139). Las películas de Rocha, de este modo, constituyen una interrogación incisiva de su coyuntura histórica, desde la perspectiva del Tercer Mundo: su fuerza de intervención radica en la especificidad formal de un cine que apunta a la ruptura artística con el sentido común, con las convenciones discursivas y sociales de la cultura hegemónica, pero que a la vez resiste cualquier nueva estabilización esencialista de una tradición cultural nacionalista.

1. Todas las citas de Di-Glauber corresponden a traducciones propias.

\section{IV}

En una entrevista de 1981, Rocha declara haber descubierto, con la filmación del documental Di-Glauber (1977), el aspecto eminentemente visual del cine, el cine como visión, color, imagen, sonido, ya por completo desligado del guión, de la novela o el ensayo (Rocha, 2011:310). Dice el mismo Rocha, mediante el recurso del voice-over (voz superpuesta o sobrevoz), en Di-Glauber: "Despertando en la mañana, recibo el impacto de la noticia de la muerte de Di [Cavalcanti] y decido realizar un film, una palabra de bienvenida para las personas que no conocieron a Di Cavalcanti y que se encontraban desinformadas". ${ }^{1}$ Rocha acompaña la primera toma del documental -un travelling de las inmediaciones del Museo de Arte Moderno de Río de Janeiro, donde se realiza el funeral de Di Cavalcanti- con la lectura de un artículo aparecido posteriormente en el Jornal do Brasil: "Filmación causa escándalo; irrita a familiares y amigos". La siguiente toma se desplaza a través del ataúd de Di Cavalcanti, para detenerse en la estática imagen de su rostro; inmediatamente, se yuxtapone la vista de una obra del propio pintor, exhibida en el mismo museo. Al pasaje entre una y otra toma se agrega la voz de Rocha, en un auto-reflexivo comentario meta-fílmico: "Ahora primer plano de su rostro. [...] 2, 3, 4, 5, 6, 7, 8, 9, 10, 11, 12, jcorte! [...] Cineasta Glauber Rocha está parado junto al ataúd de Di Cavalcanti en su funeral en el Museo de Arte Moderno". Con el montaje del primer plano de Di Cavalcanti y el plano general de su cuadro en exposición, Rocha exhibe el cadáver tal como el museo exhibe su obra pictórica. Sumada la presencia 


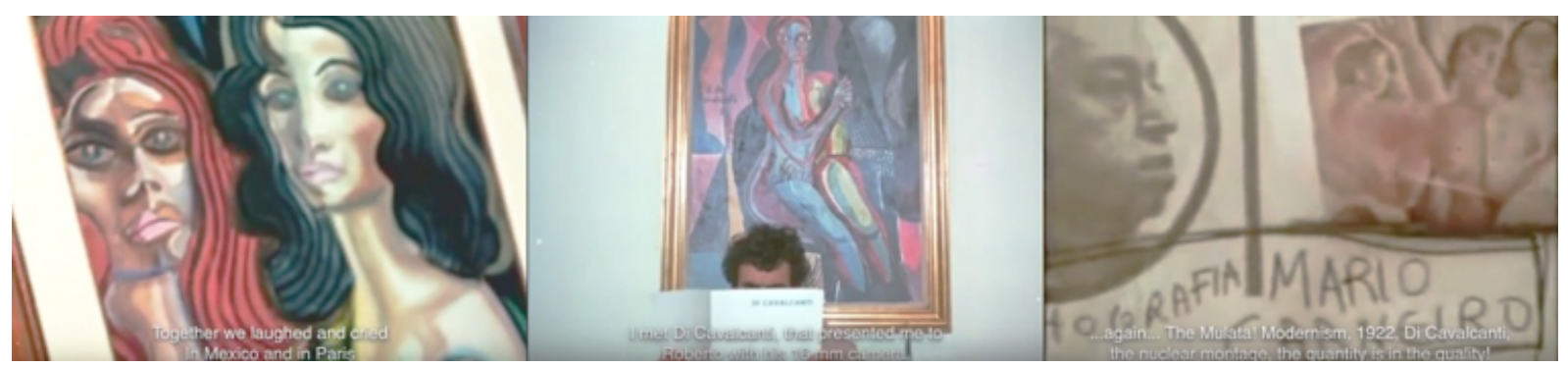

autoconsciente del propio director -a través de su voice-over y del escándalo suscitado por su filmación, con tintes performáticos, del funeral-, el dispositivo fílmico sustrae la figura y la obra de Di Cavalcanti a toda posible neutralización por parte del museo, las reclama excéntricas a las lógicas de archivo aspirantes a estabilizar una tradición. Rocha, de este modo, encuentra el lugar de su propia inscripción en el archivo, un lugar fallado, desde una negatividad irreductible que no aspira a salvar una obra y una vida, las de Di Cavalcanti, de un ulterior olvido, sino que se erige como testimonio y apertura de ellas a la contemporaneidad de una experiencia cinematográfica. Si el funeral de Di Cavalcanti en el museo metaforiza la entrada definitiva de su obra, y por consiguiente su anquilosamiento, en el archivo y tradición cultural del Brasil, Rocha hace de su film una intervención en primera persona de este archivo: devuelve, tanto al arte de Di Cavalcanti como a su propio documental, la fuerza irruptiva de presente que el velorio y el museo sugerirían neutralizar.

Frente a la clausura trascendente que la consignación en el archivo supone para la figura de Di Cavalcanti, Rocha opta por una subversión inmanente del orden cultural brasileño: su testimonio opera en los términos afectivos de la amistad y la camaradería artística. Rocha recorre, cámara en mano, los cuadros de Di Cavalcanti exhibidos en el museo: el movimiento enredado de la cámara, los abruptos acercamientos a detalles puntuales, dotan de vivacidad a su obra mientras su comentario rememora momentos compartidos: "Juntos tomamos champagne, mezcal, whisky, paraty. Juntos reímos y lloramos en México y París". Luego, el mismo Rocha se visibiliza en el cuadro fílmico, con un catálogo del pintor en mano; explicita así una reflexión autoconsciente que alcanza su climax en la última escena del documental: condensa su intervención del museificado archivo del arte brasileño en el retrato de una lámina casera, asociada a la enumeración con que la voz de Rocha reescribe el trayecto vital y estético de Di Cavalcanti: "iLa mulata, Modernismo, 1922, Di Cavalcanti, el montaje nuclear, la cantidad está en la calidad!". Significativamente, durante la filmación del cortejo fúnebre hacia al cementerio, el recurso del voice-over se desdobla y yuxtapone, en sí mismo, dos posiciones enunciativas: la lectura circunspecta del artículo del Jornal do Brasil, recuento elegíaco de la carrera del pintor, se alterna con interrupciones súbitas, gritos de Rocha que lo escanden y subvierten: "Tras crear la Bienal de São Paulo en 1951, su arte declina en oposición simétrica a Volpi, cuyo prestigio asciende desde el momento en que dividió ex-echo... ¡Grandes cuestiones metafísicas!”.

En Di-Glauber, Rocha hace del montaje un recurso análogo a las yuxtaposiciones de Di Cavalcanti entre contexto modernizador y cultura autóctona: las tomas exteriores del museo plasman la velocidad del tráfico urbano, mientras que, al focalizar en los detalles de Favela (1958), el voice-over acompaña el deslizamiento del cuadro por los barrios cariocas retratados, en colores y formas vivaces y desproporcionadas: "Los barrios son renovados: Botafogo, Glória Hotel, Copacabana y Catete". En "Eyzenstein y la revolución soviétyka", un artículo de 1981, Rocha destaca las posibilidades estéticas abiertas por la conjunción eisensteniana de música e imagen: "Múzyka es una Heuztoria espacio-temporal polisignificante, porque no describe [...] sino que Emociona. La sugestión sonora de la Música, ruidosa o armónica, libera 


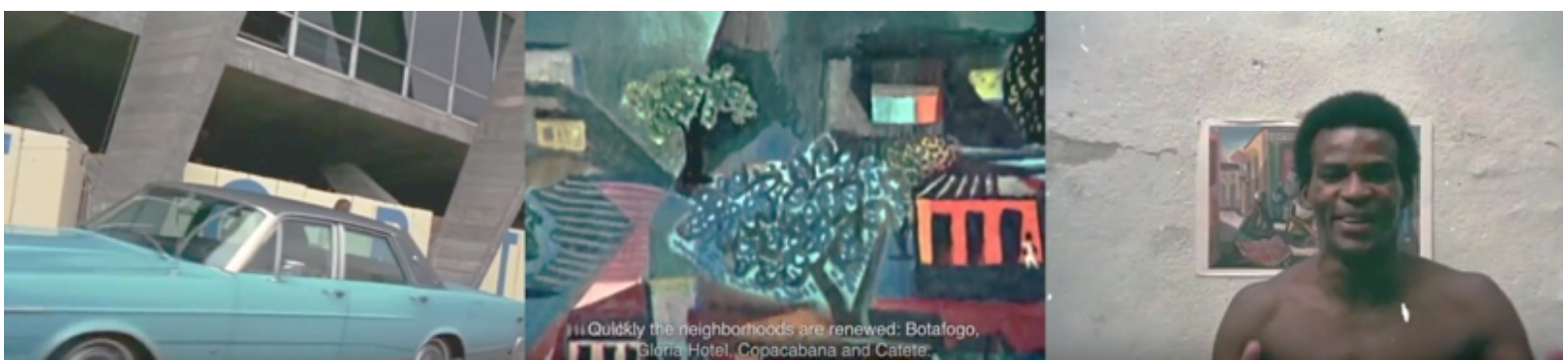

nuevas contradicciones al ser montada sobre la imagen naturalista o metafórica del cine" (Rocha, 2011: 172). El montaje de imagen y música, en Di-Glauber, constituye un contrapunto estético conforme a la intervención de Rocha en el archivo cultural del Brasil: entre las imágenes del funeral y de las pinturas de Di Cavalcanti, se inmiscuyen tomas del actor negro Antônio Pitanga, en torso desnudo y alegre baile; esta reivindicación de la cultura mulata se complementa con el acompañamiento musical de la samba carnavalesca O Teu Cabelo Não Nega.

Ivana Bentes recupera el concepto de "trance", ejemplarmente presente en el título de la célebre Tierra en trance (1967), para indicar que en él se condensa la seña de identidad del pensamiento y el cine de Rocha: "El trance es la transición, el paso, el convertirse y la posesión. Para entrar en crisis o trance tienes que dejarte cruzar, ser poseído, por otro. Glauber hace del trance una forma de experimentación y conocimiento. Entrar en trance es entrar en fase con un objeto o situación, es saber desde dentro" (Bentes, 2002). El trance se revela como rito de pasaje en el seno de una tradición, pasaje cuya meta no acaba por cristalizarse en una nueva identidad trascendente, sino que se reafirma, de un modo inmanente, como gesto de resistencia inconcluso y vuelto sobre sí. Rocha no recurre al trance para tornarlo una temática a tratar, sino para cifrar en él un procedimiento formal. La antropofagia teórico-cinematográfica de Di-Glauber, encuentra, de este modo, su concretización en un barroquismo estilístico que hace de la cámara en mano, del montaje y de la samba, la celebración de un trance estético. En el estreno del film, Rocha distribuye un texto donde afirma una concepción festiva de la muerte: "Golpeado por la tristeza de un acto que debería ser festivo en todos los casos (y sobre todo en el caso de un genio popular como Emiliano Di Cavalcanti) proyecté el Ritual Alternativo; Mi Funeral Poético, [...] el símbolo de la Vida" (Flores, 2012). El montaje de música e imagen, deglutido a partir de Eisenstein, habilita expropiar la figura y la obra de Di Cavalcanti a la reclusión museificadora del archivo nacional: el baile y el ritmo festivo hacen de la pulsión de muerte, que Derrida ubica en el seno de todo archivo, una vía lúdica y corporal, alineada con el legado antropófago oswaldiano, de subvertir un orden cultural que conserva y anquilosa, precisamente al conservar, expresiones vivas del arte brasileño.

Para Alain Badiou, el arte del siglo XX asume el puro presente como manifestación última de valor rupturista: al ser potencia intensa de comienzo, las vanguardias asumen una paradójica concepción temporal, condensada en sus manifiestos: "el manifiesto es la reconstrucción, en un futuro indeterminado, de aquello que, por ser del orden del acto, de la fulguración fugaz del instante, no se deja nombrar en presente" (Badiou, 2005: 175). Glauber Rocha, en Di-Glauber, reactualiza la potencia de presente de los manifiestos de Oswald de Andrade: al recuperar procedimientos propios del Modernismo, reactiva la pulsión de muerte subyacente al archivo cultural del Brasil, su film deviene intervención en primera persona y con él descoloca la museificación de la obra de Di Cavalcanti: "Rocha siente a Di Cavalcanti como un aglutinador de la 
memoria del pueblo, y esa sería precisamente su intención autoral como participante del nuevo cine brasileño" (Flores, 2012). La antropofagia como horizonte estéticofilosófico le permite leer el archivo a contrapelo, para así arrebatar la tradición al conformismo y afirmar la desarticulación inmanente de cualquier eventual clausura esencialista. Como dice en un fragmento titulado "Diario íntimo", publicado en 1970 en la revista francesa Positif: "es necesario que el fuego devore al Cinema Novo como Yara devora a Macunaíma. Sin embargo, antes de ser devorado, [...] debe devorar la estupidez y el esnobismo de nuestros intelectuales que son devorados por la cultura" (Rocha 2011: 129). En definitiva, desde el Manifiesto Pau-Brasil hasta llegar a Di-Glauber, se juegan las posibilidades de intervenir el archivo nacional dominante y descomponer toda lógica de petrificación de la identidad brasileña. 


\section{Q Bibliografía}

》Aguilar, G. (2010). Por una ciencia del vestigio errático (Ensayos sobre la antropofagia de Oswald de Andrade). Buenos Aires, Editorial Grumo.

» Amaral, A. (ed.) (1978). Prólogo. En Arte y arquitectura del modernismo brasileño (1917-1930). Caracas, Ayacucho.

»Andrade, M. de. (1978). Di Cavalcanti. En Amaral, A. ob. cit.

"Andrade, O. de. (2008). Escritos antropófagos. Buenos Aires, Corregidor.

»Antelo, R. (2014). Imágenes de América Latina. Buenos Aires,EDUNTREF.

»Badiou, A. (2005). El siglo. Buenos Aires: Manantial.

"Bentes, I. (2002). Terra de fome e sonho: o paraíso material de Glauber Rocha. (Consulta:6-12-2019). Disponible en <http://www.bocc.ubi.pt/pag/bentes-ivana-glauber-rocha.html>.

»Derrida, J. (1997). Mal de archivo. Una impresión freudiana. Madrid, Trotta.

»Flores, S. (2012). Di-Glauber: juntos en el arte y en la muerte. En Cine Documental, núm. 6. (Consulta: 6-12-2019). Disponible en <http://revista.cinedocumental.com.ar/6/articulos_03.html>.

»Link, D. (2009). Fantasmas. Buenos Aires, Eterna Cadencia.

»Palti, E. J.. (1996). Imaginación histórica e identidad nacional en Brasil y Argentina. Un estudio comparativo. En Revista Iberoamericana, vol. LXII, núm. 174, pp. 47-69.

» Rocha, G. (1977). Di-Glauber. Río de Janeiro,Embrafilme.

»Rocha, G. (2011). La revolución es una eztétyka. Buenos Aires, Caja Negra. 